\title{
PENINGKATAN DAYA SAING USAHA OLAHAN PANGAN (PEYEK KACANG DAN EMPING MELINJO)
}

\author{
Rita Kusumawati, Taufik Akhbar, Alien Akmalia \\ Fakultas Ekonomi dan Bisnis, Universitas Muhammadiyah Yogyakarta \\ kusumawatirita@yahoo.com,taufikakhbar@gmail.com,akmalia_alien@yahoo.com
}

\begin{abstract}
This program aims to help partners to be more independent and improve their business competitiveness. Business partners in this program are Peyek Bu Dalidjo and melinjo chips "Sari Melinjo" were located in Kamijoro. Kamijoro is located in Sendangsari Village, Pajangan sub-district, Bantul Regency, Yogyakarta. This hamlet has located $\pm 15 \mathrm{Km}$ to the southwest of Yogyakarta, exactly $8 \mathrm{~km}$ west of Bantul. The village of Kamijoro is located in the heart of the capital of the Pajangan sub-district. The live hoods of the people of Kamijoro are quite diverse; not a few among the inhabitants of this hamlet who make a living as entrepreneurs, including both partners in this program. The two partners' problems include 1) limited marketing aspects; 2) An improper business nameplate; 3) unfavorable business financial administration. The results of this program are 1) Peyek bu Dalidjo and melinjo chips "Sari Melinjo" has an attractive label design and packaging; 2) Both partners expand marketing strategies through online marketing media and offline media; 3) both partners have a proper business name board; 4) partners understand and can make business cash flow records
\end{abstract}

Keywords: competitiveness, melinjo chips, peyek kacang, Bantul.

\begin{abstract}
Abstrak
Program ini bertujuan untuk membantu mitra agar lebih mandiri dan meningkatkan daya saing usahanya. Mitra usaha dalam program ini adalah usaha peyek "bu Dalijo” dan usaha emping "Sari Melinjo” yang terletak di Kamijoro. Dusun Kamijoro terletak di Desa Sendangsari, kecamatan Pajangan, Kabupaten Bantul Daerah Istimewa Yogyakarta. Dusun ini terletak $\pm 15 \mathrm{Km}$ di sebelah barat daya kota Yogyakarta yang tepatnya berada di $8 \mathrm{Km}$ sebelah barat kota Bantul. Dusun Kamijoro terletak di jantung Ibu kota kecamatan Pajangan. Mata pencaharian penduduk Kamijoro cukup beragam, tidak sedikit diantara penduduk dusun ini bermata pencaharian sebagai wirausaha, termasuk kedua mitra dalam program ini. Permasalahan yang dihadapi oleh kedua mitra antara lain: 1) aspek pemasaran yang masih terbatas; 2) papan nama usaha yang tidak layak; 3) administrasi keuangan usaha yang belum baik. Metode yang digunakan untuk menyelesaikan permasalahan mitra adalah melalui pelatihan, pendampingan dan bantuan peralatan. Hasil dari program ini adalah: 1) usaha peyek bu Dalijo dan emping sari melinjo mempunyai disain label dan kemasan yang menarik; 2) kedua mitra memiliki media pemasaran online. 3) kedua mitra memiliki papan nama usaha yang layak; 4) mitra paham dan mampu membuat catatan arus kas usaha.
\end{abstract}

Kata kunci: daya saing usaha, peyek kacang, emping melinjo, Bantul. 


\section{PENDAHULUAN}

Usaha mikro kecil dan menengah (UMKM) merupakan pelaku ekonomi yang memegang peranan penting bagi perekonomian Indonesia karena menyerap tenaga kerja yang banyak dan terbukti sektor inilah yang mampu bertahan ketika Indonesia mengalami krisis moneter sekitar tahun 1998. Hasil penelitian yang dirilis Bank Indonesia menunjukkan bahwa kinerja UMKM Indonesia dibanding UMKM di negara ASEAN masih relatif rendah dan daya saing UMKM pun masih relatif rendah (Bank Indonesia, 2016). Pemerintah Indonesia melalui Disperindagkop, Bank Indonesia dan beberapa lembaga telah melakukan berbagai upaya untuk meningkatkan kinerja dan daya saing UMKM. Tapi tentu saja itu tidak cukup menjangkau semua UMKM. Upaya-upaya yang bisa dilakukan untuk meningkatkan daya saing UMKM antara lain melalui : peningkatan produktivitas, menciptakan kemudahan berusaha, akses permodalan, penciptaan akses pasar, dan dukungan infrastruktur. Pelaku usaha juga perlu dibekali manajemen usaha termasuk didalamnya manajemen pemasaran dan manaejmen keuangan. Disinlah peran perguruan tinggi melalui program pengabdian dosen dibutuhkan untuk bisa mendampingi dan memberi pengetahuan terkait sehingga kinerja dan daya saing UMKM meningkat.

$$
\text { Mitra dalam program }
$$

pengabdian masyarakat ini adalah produk olahan pangan yang berlokasi di daerah Pajangan, Bantul. Mitra yang pertama adalah Usaha Peyek Kacang
Bu Dalidjo, mitra kedua adalah Usaha Emping “Sari Mlinjo" . lokasi usaha kedua mitra terletak di daerah Kamijoro, Sendangsari, Pajangan Bantul. Peyek Kacang $\mathrm{Bu}$ Dalidjo adalah salah satu usaha mikro yang sehari-hari memproduksi dan menjual peyek kacang. Usaha yang dimiliki oleh Ibu Sutiyah ini sehari-hari mampu memproduksi peyek kacang sebanyak 300 bungkus. Usaha ini sebenarnya merupakan usaha turunan dari keluarga beliau. Usaha dijalankan dengan peralatan yang sudah tidak layak. Produk peyek kacang dikemas dengan menggunakan cara yang sederhana yaitu menggunakan plastik dan label apa adanya. Papan nama usaha yang dimiliki usaha ini juga sudah terlihat usang sehingga sulit untuk dibaca. Saat ini Ibu Sutiyah dibantu oleh 2 orang karyawan yang berasal dari desa setempat. Dalam menjual peyek kacangnya, Ibu Sutiyam mematok harga Rp 3000 per bungkus. Proses bisnis yang dilakukan oleh Ibu Sutiyem dengan menggunakan sistem business to business dimana Ibu Sutiyem menjual ke toko-toko yang ada di sekitar tempat produksi.

Mitra kedua yaitu usaha emping melinjo “Sari Mlinjo” yang berlokasi sekitar 200 meter dari lokasi mitra 1. Usaha ini dimiliki oleh Ibu Surani. Sehari-sehari ibu Surani bisa memproduksi emping $10 \mathrm{~kg}-25 \mathrm{~kg}$ tergantung kondisi pasar. Ibu Surani mendapatkan bahan baku melinjo dari daerah Imogiri dan Godean. Saat ini Ibu Surani dibantu oleh 8 orang karyawan yang merupakan tetangga beliau sendiri. Pemasaran emping melinjo Ibu Surani 
masih sangat terbatas. Selama ini emping dijual di warungnya sendiri dan juga dipasarkan di wilayah Magelang, Muntilan dan Borobudur. Dalam memasarkan produknya Ibu Surani biasanya menjual dalam partai besar, sedangkan untuk partai kecil usaha ini belum meiliki kemasan dan disain label yang menarik. Papan nama yang dimiliki usaha ini juga sangat sederhana, hanya ditulis tangan diatas papan triplek. Dalam menjalankan usahanya, ibu Surani belum memiliki pencatatan administrasi keuangan, sehingga pemilik tidak pernah mengetahui posisi keuangan usahanya apakah untung atau tidak.

Untuk mengatasi permasalahan tersebut perlu adanya optimalisasi pemasaran dan pencatatan administrasi keuangan yang tertib. Kotler (2009) mendefinisikan pemasaran sebagai suatu proses sosial, dimana individu dan kelompok mendapatkan apa yang mereka butuhkan dan mereka inginkan dengan menciptakan dan mempertahankan produk dan nilai dengan individu dan kelompok lainnya. Pemasaran bagi suatu usaha memiliki peran penting, diantaranya adalah: segala informasi tentang produk dapat disampaikan ke konsumen; dapat menjelaskan fungsi, manfaat, dan keunggulan sebuah produk; dan bisa menginformasikan produk dan layanan baru kepada konsumen (Fadjar, 2016).

Pencatatan keuangan sangat penting bagi suatu usaha, diantaranya adalah : memudahkan pemilik untuk mengurai masalah terkait usaha, sebagai bahan pertimbangan dalam pengambilan keputusan terkait jalannya usaha, agar memudahkan pemilik dalam mengontrol jalannya usaha dan sebagai bahan untuk mengajukan tambahan modal kepada investor atau pemberi pinjaman (Sandy, 2017).

Berdasarkan permasalahan yang dihadapi, maka program ini difokuskan pada program peningkatan daya saing usaha melalui optimalisasi pemasaran dan administrasi keuangan dengan rincian kegiatan yaitu: (1) Peremajaan alat produksi; (2) Perbaikan label dan kemasan produk; (3) Pengadaan papan nama; (4) Pendampingan pemasaran online dan offline.; (5). Pendampingan administrasi keuangan usaha.

Tujuan dari program ini adalah membantu mitra agar lebih mandiri dan meningkatkan daya saing usahanya.melalui optimalisasi pemasaran dan pencatatan administrasi keuangan. Kegiatan pemasaran yang optimal diharapkan akan memperluas jangkauan pemasaran sehingga omset penjualanpun akan meningkat.

\section{METODE PELAKSANAAN}

Metode pelaksanaan program peningkatan daya saing usaha untuk kedua mitra bisa dilihat pada tabel 1 dan tabel 2.

Tabel 1. Metode Pelaksanaan Pemecahan Masalah Usaha Peyek bu Dalijo.

\begin{tabular}{llll}
\hline No & \multicolumn{2}{l}{ Permasalahan } & Metode \\
& Mitra & Pelaksanaan \\
\hline $\mathbf{1}$ & \multicolumn{2}{l}{ Keterbatasan } & Mitra didorong \\
& alat. Alat & untuk \\
& \multicolumn{2}{l}{ penggorengan } & pengadaan alat \\
& yang selama & penggorengan \\
& ini dimiliki & (wajan) supaya \\
& sudah & tidak & hasil produk \\
\hline
\end{tabular}




\begin{tabular}{|c|c|c|}
\hline & $\begin{array}{l}\text { layak dan } \\
\text { berwarna } \\
\text { hitam. }\end{array}$ & $\begin{array}{l}\text { lebih terjaga } \\
\text { kualitasnya }\end{array}$ \\
\hline 2 & \begin{tabular}{l}
\multicolumn{2}{l}{ Kemasan } \\
produk mitra \\
yang kurang \\
menarik serta \\
media promosi \\
yang kurang.
\end{tabular} & $\begin{array}{l}\text { Mitra akan } \\
\text { dilatih dan } \\
\text { didampingi } \\
\text { membuat } \\
\text { kemasan dan } \\
\text { label produk } \\
\text { yang menarik } \\
\text { dan juga } \\
\text { dibantu } \\
\text { pengadaan alat } \\
\text { perekat } \\
\text { kemasan } \\
\text { (sealer), mitra } \\
\text { akan dilatih } \\
\text { dan } \\
\text { didampingi } \\
\text { dalam } \\
\text { membuat } \\
\text { media } \\
\text { pemasaran } \\
\text { melalui } \\
\text { internet antara } \\
\text { lain lewat } \\
\text { Facebook dan } \\
\text { Bedukmutu. }\end{array}$ \\
\hline 3 & $\begin{array}{lr}\text { Papan } & \text { nama } \\
\text { usaha } & \text { yang } \\
\text { dimiliki } & \text { oleh } \\
\text { mitra } & \text { sudah } \\
\text { tidak } & \text { bagus } \\
\text { sehingga } & \text { sulit } \\
\text { terbaca } & \text { oleh } \\
\text { kosumen } & \text { yang } \\
\text { melintas } & \text { di } \\
\text { tempat } & \text { usaha } \\
\text { beliau. } & \end{array}$ & 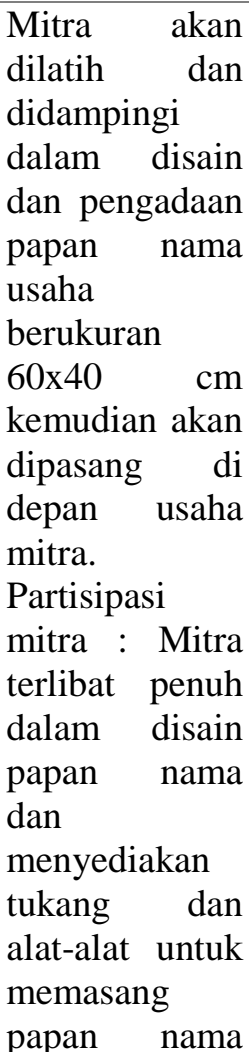 \\
\hline
\end{tabular}

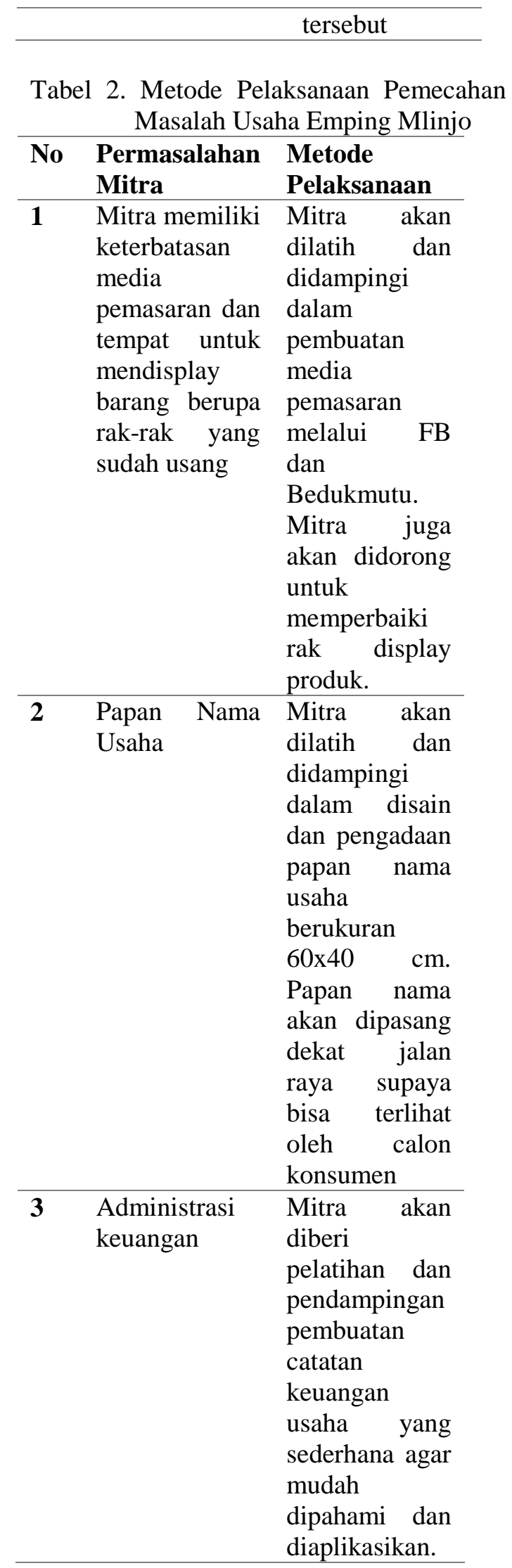




\section{HASIL DAN PEMBAHASAN}

\section{Optimalsisasi Pemasaran}

Pemasaran merupakan proses menyampaikan barang atau jasa yang dihasilkan suatu bisnis kepada pelanggan dengan melibatkan semua aktivitas yang dapat mengikat pelanggan dan membuatnya loyal (Pambudy R, dkk, 2017). Di lingkungan bisnis yang persaingannya semakin kompetitif ini, pelaku bisnis dituntut untuk kreatif, inovatif dan bisa mengikuti perubahan yang ada. Pemasaran yang dilakukan kedua mitra masih dilakukan secara sederhana. Produk diberi label dan kemasan yang sederhana, dijual di warung milik sendiri dan di warung sekitar sehingga omset penjualan masih terbatas Untuk mengantisipasi persaingan bisnis yang semakin kompetitif dan untuk mengembangkan usaha emping "Sari Melinjo”, dan usaha 'peyek bu Dalijo” maka dalam pendampingan optimalisasi pemasaran ini dilakukan beberapa kegiatan, yaitu: pelatihan dan pendampingan pembuatan label dan kemasan produk, pelatihan dan pendampingan pemasaran offline dan online, dan pembaruan papan nama, pembarauan rak display dan pelatihan dan pendampingan pencatatan administrasi keuangan.

\section{a. Pembuatan Label dan Kemasan yang menarik}

Produk yang berkualitas perlu didukung dengan label dan kemasan yang menarik. Label adalah tampilan sederhana pada produk atau gambar yang dirancang dengan rumit yang merupakan satu kesatuan dengan kemasan (Kotler, 2009). Kemasan adalah suatu bentuk kegiatan yang melibatkan desain serta produk, sehingga kemasan ini dapat berfungsi agar produk di dalamnya dapat terlindungi (Kotler dan Amstrong, 2004). Label memiliki manfaat penting bagi suatu produk. Manfaatnya antara lain adalah: berfungsi sebagai sarana komunikasi produsen kepada konsumen tentang hal-hal yang perlu diketahui oleh konsumen tentang produk tersebut, terutama hal-hal yang kasat mata atau tak diketahui secara fisik; memberi petunjuk yang tepat pada konsumen hingga diperoleh fungsi produk yang optimum; sarana periklanan bagi produsen; memberi rasa aman bagi konsumen (Riadi M, 2018). Sedangkan kemasan memiliki manfaat antara lain: sebagai identitas produk, untuk menambah citra produk dan daya tarik pembeli, sebagai sarana infromasi dan iklan, dan beberapa manfaat lainnya.

Dalam program ini, tahap pertama yang dilakukan adalah memberikan penyuluhan kepada pelaku usaha akan arti pentingnya "Label" dan "Kemasan” bagi suatu produk dalam menunjang pemasarannya.

Setelah itu, tim mendampingi kedua mitra untuk membuat disain label dan packaging untuk produk emping "Sari Melinjo".
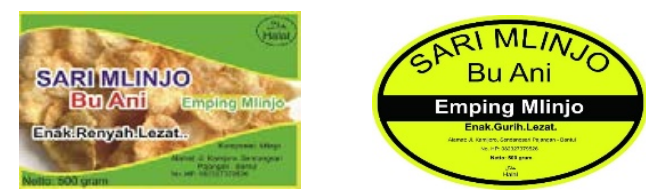

Label produk Emping "Sari Melinjo” 

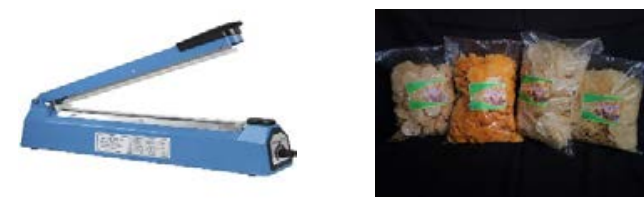

Peralatan pengemasan "sealer"

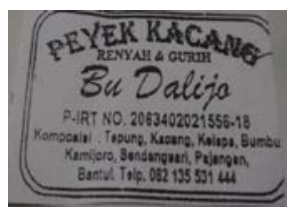

Label peyek kacang "Bu Dalijo” sebelum Pendampingan

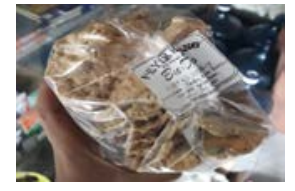

Kemasan peyek "Bu Dalijo" sebelum pendampingan

\section{b. Pelatihan dan Pendampingan Pemasaran offline dan online}

Pemasaran online merupakan praktik memanfaatkan saluran berbasis web untuk menyebarkan pesan tentang merk, produk, atau layanan usaha ke calon pelanggannya (Hestanto, 2018). Tujuan pemasaran online ini adalah untuk menjangkau calon pelanggan memalui saluran internet tanpa batasan wilayah.

Pada program ini, awalnya tim memberikan pemahaman tentang pentingnya pemasaran online kepada pelaku usaha dengan mengajak untuk mengikuti pelatihan online. Setelah itu, tim mendampingi kedua mitra dalam pembuatan akun sosial media yang bisa digunakan untuk pemasaran online seperti facebook, instagram. Selain itu tim juga membantu kedua mitra agar produk emping "Sari Melinjo" dan peyek kacang "Bu Dalijo: terdaftar di lapak Beduk Mutu UMY. Terakhir, tim melakukan pendampingan agar pelaku usaha dalam hal ini bu Ani dapat mengoperasikan pemasaran online tersebut.

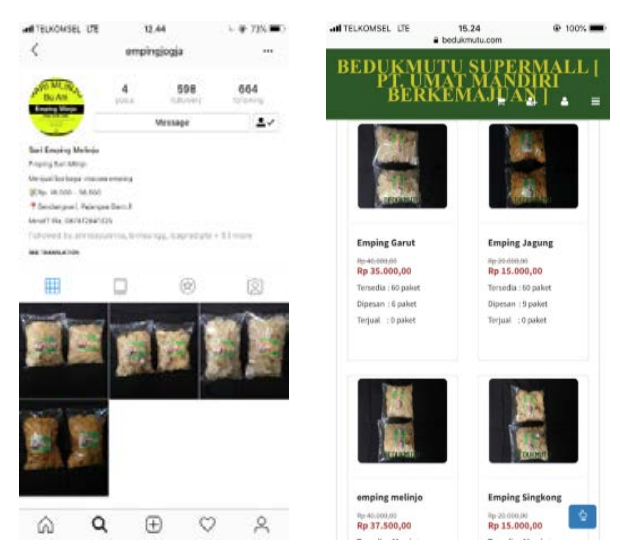

Pemasaran Pemasaran online di online melalui bedukmutu UMY instagram
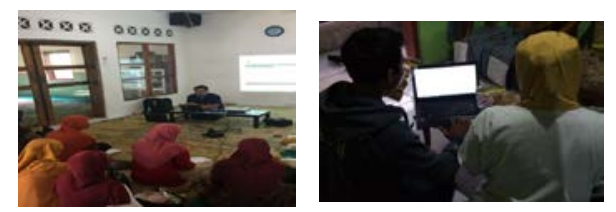

Pelatihan

Pendampingan

Pemasaran online pemasaran online melalui

bedukmutu
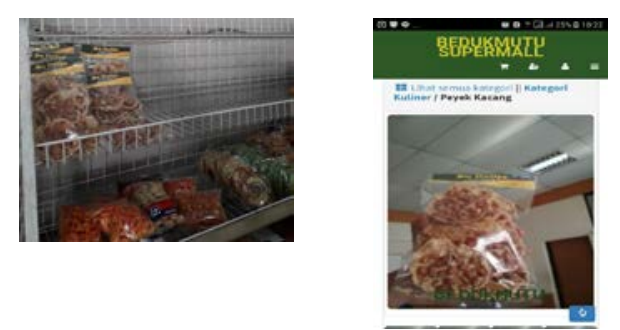

Pemasaran offline Pemasaran online di dengan ditiitip di bedukmutu UMY toko OMI 


\section{c. Pembuatan Papan Nama}

Papan nama penting artinya bagi suatu usaha, selain sebagai penunjuk lokasi usaha juga merupakan media promosi bagi suatu usaha. Papan nama yang menarik dan jelas serta mudah dibaca akan akan memudahkan konsumen untuk menemukan lokasi usaha. Papan nama yang dimiliki usaha emping "Sari Melinjo" sangat tidak layak sehingga tim mendorong pemilik usaha untuk membuat papan nama yang baru yang lebih menarik. Papan nama yang dimiliki oleh bu Dalijo sudah terlihat usang dan tulisannya pudar sehingga tidak terlihat jelas tulisannya. Kegiatan dimulai dengan mendampingi pemilik usaha dalam mendesign papan nama yang baru, kemudian membuat dan memasang papan nama tersebut di pinggir jalan di dekat lokasi usaha.

\section{d. Pembuatan Rak Display}

Rak Display juga merupakan hal yang perlu diperhatikan dalam suatu usaha. Produk yang tertata dengan rapi memudahkan pembeli dan juga memudahkan bagi pemilik usaha. Rak dispaly yang dimiliki usaha emping "Sari Melinjo” sudah tidak layak. Karena itu, tim mendorong pemilik usaha untuk memperbarui rak display dan memberi masukan dalam menata ulang disain ruangan toko agar lebih terlihat bagus dan menarik bagi pembeli.
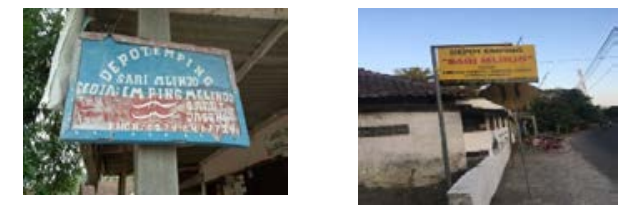

Papan nama usaha

“Sari Melinjo” lama
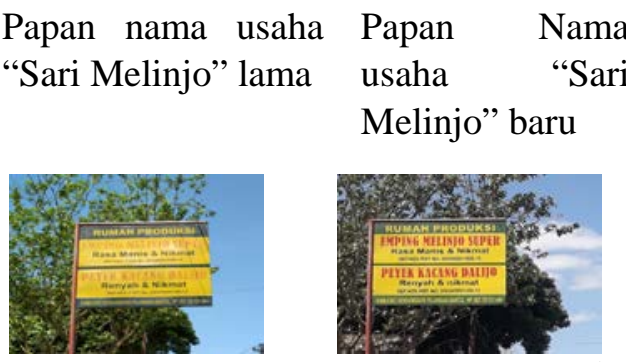

Papan nama

usaha peyek "Bu

Dalijo” lama

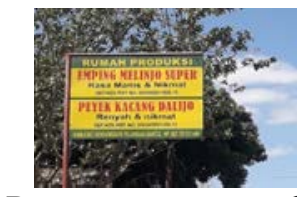

Papan nama usaha peyek "Bu Dalijo" baru
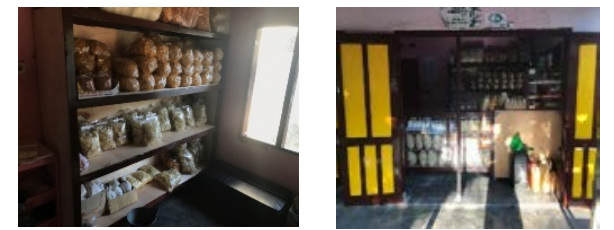

Rak display bagian belakang dan bagian depan

\section{Pelatihan dan Pendampingan Administrasi Keuangan}

Usaha emping "Sari Melinjo" selama ini tidak melakukan perencanaan keuangan usaha mereka dengan baik dan juga tidak melakukan catatan administrasi keuangan, bahkan seringkali keuangan usaha dan keuangan rumah tangga tercampur. Hal ini berdampak pada usaha yang stagnan atau tidak berkembang karena dana yang dimiliki pada awalnya tidak dikelola dengan baik. Karena itu dalam program ini tim melakukan pelatihan pengelolaan keuangan bagi bu Ani beserta ibu ibu yang tergabung dalam KUK Aisiyah Pajangan. Setelah mengikuti pelatihan, bu Ani didampingi dalam pencatatan administrasi keuangannya. 


\section{Pembaruan alat produksi}

Berdasarkan hasil observasi usaha peyek bu Dalijo memiliki keterbatasan alat. Alat penggorengan yang selama ini dimiliki sudah tidak layak dan berwarna hitam. Oleh karena itu untuk menjaga kualitas produk peyek, maka kami mendorong mitra untuk mengganti alat penggorengan dengan yang baru. Selain itu untuk membuat kemasan lebih bagus dan menarik bagi pembeli, mitra dibantu dalam pengadaan sealer.

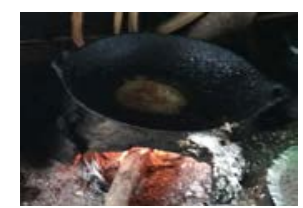

Penggorengan yang lama

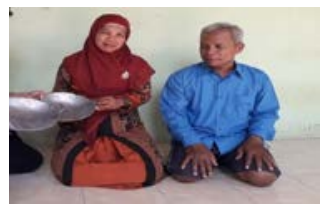

Penggorengan yang baru

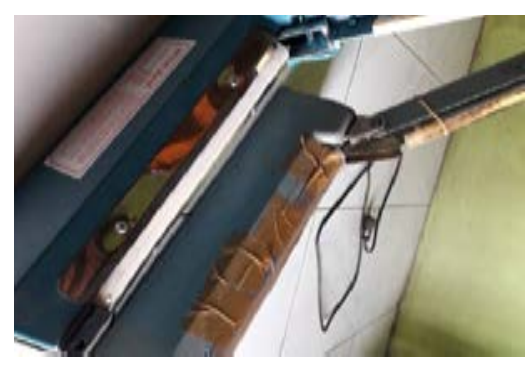

Sealer baru dan sealer lama

\section{SIMPULAN}

Kesimpulan dari pelaksanaan program PKM ini adalah:

1. Terbangunnya kesadaran mitra untuk meningkatkan daya saing melalui beberapa aspek.

2. Tersedianya peralatan yang menunjang kegiatan produksi.

3. Terbangunnya kesadaran akan pentingnya label, kemasan dan papan nama dalam menunjang kegiatan pemasaran
4. Terbangunnya pemahaman akan pemasaran online

5. Terbangunnya kesadaran dan pemahaman akan pentingnya pencatatan administrasi keuangan usaha.

\section{UCAPAN TERIMAKASIH}

Pada kesempatan ini kami menyampaikan terimakasih kepadaIbu Hanifah, pengurus Aisiyah Pajangan Bantul, Ibu-ibu pengurus Kelompok Usaha Kecil Aisiyah Pajangan Bantul, LP3M Universitas Muhammadiyah Yogyakarta yang telah mendanai program pengabdian masyarakat ini dengan skema Program Kemitraan Masyarakat (PKM).

\section{DAFTAR PUSTAKA}

Bank Indonesia, 2016, Pemetaan dan Strategi Peningkatan Daya Saing UMKM dalam menghadapi Masyarakat Ekonomi ASEAN (2015) dan Pasca MEA (2025), https://www.bi.go.id/id/umkm/ penelitian/nasional/kajian/Page s/Pemetaan-dan-StrategiPeningkatan-Daya-SaingUMKM-dalam-MenghadapiMasyarakat-Ekonomi-ASEAN(2015)-dan-Pasca-MEA2025.aspx.

Fadjar, Pentingnya Pemasaran Dalam Sebuah Usaha Bisnis, http://realfajar.blogspot.com/20 12/07/pentingnya-pemasarandalam-sebuah-usaha.html 
Rita Kusumawati, dkk. Peningkatan Daya Saing Usaha Olahan Pangan...

Pambudy R, dkk, 2017 Kewirausahaan dan Manajemen Bisnis Kecil, Idemedia.

Hestanto, 2018, Konsep Dasar Pemasaran Online, https://www.hestanto.web.id/k onsep-dasar-pemasaran-online/

Kotler, 2009, Manajemen Pemasaran,Edisi 13, Erlangga

Kotler \& Amstrong, 2004, Dasar-dasar Pemasaran, Edisi Kesembilan, Indeks.

Riadi M, 2018, Pengertian, Fungsi, Jenis dan Ketentuan Label Produk, https://www.kajianpustaka.com /2018/03/pengertian-fungsijenis-dan-ketentuan-label.html

Sandy, W, 2017, Tata Kelola Administrasi Keuangan Sederhana Bagi UMKM, dan Kelompok Usaha Bersama, https://widytaurus.wordpress.c om/2017/11/16/tata-kelola- administrasi-keuangan-

sederhana-untuk-umkm-dan-

kelompok-usaha-bersama/ 